\title{
Brain lesion and memory functioning: Short-term memory deficit is independent of lesion location
}

\author{
Carmi Schooler, Leslie J. Caplan, ANd ANdrew J. Revell \\ National Institute of Mental Health, Bethesda, Maryland \\ AND \\ Andres M. Salazar and Jordan Grafman \\ National Institute of Neurological Disorders and Stroke, Bethesda, Maryland
}

\begin{abstract}
We analyzed the effects of patterns of brain lesions from penetrating head injuries on memory performance in participants of the Vietnam Head Injury Study (Grafman et al., 1988). Classes of lesion patterns were determined by mixture modeling (L. K. Muthén \& B. O. Muthén, 1998-2004). Memory performance was assessed for short-term memory (STM), semantic memory, verbal episodic memory, and visual episodic memory. The striking finding was that large STM deficits were observed in all classes of brain-injured individuals, regardless of lesion location pattern. These effects persist despite frequent concomitant effects of depressive symptomatology and substance dependence. Smaller deficits in semantic memory, verbal episodic memory, and visual episodic memory depended on lesion location, in a manner roughly consistent with the existing neuropsychological literature. The theoretical and clinical implications of the striking, seemingly permanent STM deficits in individuals with penetrating head injuries are discussed.
\end{abstract}

In this article, we assess memory performance in Vietnam War veterans from the Vietnam Head Injury Study (VHIS; Grafman et al., 1988) who have suffered penetrating head injuries, primarily due to low-velocity shrapnel wounds. In an earlier article, we identified the optimal four-factor latent structure model underlying performance on a battery of memory tests (Herrmann et al., 2001): verbal episodic memory, visual episodic memory, semantic memory, and short-term memory (STM). In this article, we assess long-term deficits in these four memory factors and examine the relationships between patterns of memory deficit and patterns of brain injury, using the complete VHIS sample.

There is an extensive literature on the relationship between types of memory and brain structures (for a review, see Lezak, 1995). For example, performance on semantic memory tasks is commonly believed to reflect left frontal lobe functioning (see, e.g., Benton \& Hamsher, 1976; Wagner, 2002). Performance on visual episodic memory tasks reflects the functioning of both the right temporal lobe (e.g., Kimura, 1963; Smith \& Bigel, 2000) and the right frontal lobe (Wagner, 2002). Performance on verbal episodic memory tasks is assumed to reflect functioning of the left temporal lobe (Chelune \& Bornstein, 1988; Smith \& Bigel, 2000) and of the left frontal lobe (Wagner, 2002). Performance on STM tasks has been related to a variety of brain structures, including the hippocampus, the anterior cingulate, the temporal lobes, and the dorsolateral prefrontal cortex (Gerton et al., 2004; Lee, Loring, Smith, \& Flanigin, 1990; Lee, Loring, \& Thompson, 1989; Lezak, 1983, 1995; Milner, 1971; Sass et al., 1988). We note that STM, as measured by our structural equation model (SEM) latent factor, and as we use the term, is not equivalent to working memory (WM). Although STM may be functionally related to WM, and is plausibly a component of WM, STM is a more restricted function (e.g., Kane et al., 2004), one that can be differentiated and measured with psychometrically acceptable accuracy.

We report two types of analysis. In the first, the characteristics of the sample and their lesions led us to the primary analytic strategy of identifying not single delimited injury locations, but patterns of injury locations, and examining the relationships between these patterns and memory performance. In the second, more traditional approach, we compare individuals with injuries in traditionally identified regions (e.g., frontal lobe, temporal lobe), regardless of whether they have concomitant injury in other areas, with normal controls.

\section{METHOD}

\section{Participants}

The VHIS included male U.S. veterans of the Vietnam War who survived low-velocity penetrating (mostly shrapnel fragment) head injuries sustained in combat (see Grafman et al., 1988, for a more

C.Schooler, carmi.schooler@nih.gov 
extensive description). A total of 519 brain-injured men volunteered to participate for a weeklong inpatient follow-up investigation, along with 85 non-brain-injured controls who served in Vietnam during the same period. One normal control participant had no data for the memory tasks; his data were not included in these analyses, yielding a final sample size of 84 for the normal controls.

The follow-up investigation took place $12-15$ years postinjury between 1981 and 1985 at Walter Reed Army Medical Center in Washington, DC. Average age at the time of injury was $21 \pm 3$ years; average education for controls and brain injured at follow-up was $13 \pm 2$ years. It is important to note that this was a unique, young, and uniformly healthy population preinjury. In contrast to the more common closed-head injury or to civilian gunshot wounds, these veterans' lesions tend to be focal and limited to the surgical deficits delineated via computerized tomography (CT). The focal nature of the lesions and limited energy deposition in the brain by the missile injury is further supported by the relatively low incidence of traumatic unconsciousness in this group (Salazar et al., 1986).

\section{Memory Measures \\ Memory measures were based on factor scores derived from the loadings and indicators of the two-group four-factor SEM laten variable confirmatory factor analysis reported by Herrmann et al. (2001). The four latent variable memory factors are STM (includ- ing verbal, spatial, and numerical tasks), semantic memory, verbal episodic memory, and visual episodic memory. The standardized normative factor loadings for the controls, together with a descrip- tion of the constituent memory tasks, are presented in Table 1 .}

\section{Total Brain Volume and Lesion Location}

Brain volume and lesion location were determined from CT scans. In addition to the twenty-four 5-mm slices per patient, tissue around the defect was also assessed. Image analysis included both a subjective morphological interpretation and a quantitative lesion analysis. The latter involved the use of a light pen to trace the affected area on each slice. Total volume loss was calculated by summing loss areas across slices.

For each slice, identifiable structures were coded both in terms of actual area lost (loss area variables), and by the following scale (loss code variables): 1 = normal appearance, 2 = equivocal abnormal ity, 3 = definite abnormality, part of structure intact, $4=$ definite abnormality involving entire structure. This entire data set consisted of approximately 700 variables.

\section{Missing Data and Preparation of Lesion Data for Analysis}

Eight head-injured cases were dropped due to substantial missing data. Slices 11, 14, 20, and 24 were removed because of the absence of evidence of lesion. Finally, variables with 12 or fewer nonmissing or nonzero (or, in the case of loss codes, non-normal, i.e., "1") values in either loss code or loss area files were removed.

For the remaining data, missing values were imputed separately for loss codes and loss areas, using SPSS's missing value analysis with regression (for loss codes) or expectation maximization (for loss areas) only.

\section{RESULTS}

\section{Lesion Data}

\section{Data Reduction}

To create empirically meaningful variables from the hundreds of lesion variables, as well as to reduce the number of variables to conform to requirements, we began by reducing the lesion data. First, we conducted an exploratory factor analysis (EFA; Promax rotation) on lesion data; loss code and loss area variables were included in the same analysis. This analysis resulted in 79 first-order factors. Anderson-Rubin (Anderson \& Rubin, 1956) fac- tor scores were calculated for each participant, for each of these first-order factors. A second EFA on these factor scores yielded a set of 20 second-order factors. A set of Anderson-Rubin factor scores was then computed for each of these 20 second-order factors, for each participant.

\section{Mixture Model Analysis of Head Injury}

The second-order factor scores were subjected to a series of mixture-model latent-variable analyses using Mplus (L. K. Muthén \& B. O. Muthén, 1998-2004) to estimate the number of statistically distinct classes (i.e., subpopulations) that exist within our sample in terms of their patterns of brain injury. Mixture modeling "refers to modeling with categorical latent variables that represent subpopulations where population membership is not known but is inferred from the data" (B. [O.] Muthén \& L. K. Muthén, 2000, p. 117; see also B. [O.] Muthén $\&$ Shedden, 1999). Among other research uses, mixture modeling has been applied to clinical populations to identify subpopulations whose prognoses differ (B. [O.] Muthén \& L. K. Muthén, 2000).

Our best-fitting mixture model was identified using the Akaike information criterion (Akaike, 1987) and the sample-size-adjusted Bayesian information criterion (Sclove, 1987). This model divided the brain-injured veterans into 23 classes. The 23 classes included several relatively small classes and one large class $(n=303)$. With the exception of the largest class, each participant was assigned to the class that the analysis suggested was the most probable class for that individual. We then carried out a second series of mixture model analyses on the largest class. This analysis, in turn, yielded 13 classes, including another relatively large class $(n=211)$. Again, with the exception of the largest class of 211 participants, each of these 303 participants $(n=92)$ was assigned to the class that the analysis suggested was the most probable class for that individual. Finally, a series of mixture model analyses was conducted on a large class of 211, yielding nine classes. Each of these 211 participants was assigned to the class that the analysis suggested was the most probable class for that individual. Identifying descriptions of the brain-injury classes used in the analyses are provided in Table 2.

We characterized the classes with sample sizes greater than 8 by examining each class's factor loading on each of the 20 second-order factor scores, particularly those mean factor scores greater than 1.5 (i.e., greater than 1.5 standard deviations above the mean for the entire sample). If necessary, factor loadings on first-order factors were also considered. The characterizations of the major classes were then checked by one of the authors (A.M.S., a neurologist), who compared them with CT scans from each class. The resulting descriptions are included in Table 2.

\section{Comparisons of Mixture-Model Lesion Classes and Normal Controls}

Factor scores for each memory factor were computed for each participant, using his score on the relevant tasks and the factor loadings from the original analysis, as re- 
Table 1

Four Memory Factors and Their Respective Tests, Test Descriptions, and Loadings

\begin{tabular}{|c|c|c|c|}
\hline Factor Name & Test & Description & $\begin{array}{l}\text { Loading for } \\
\text { Controls }\end{array}$ \\
\hline \multirow[t]{7}{*}{ Short-term memory } & $\begin{array}{l}\text { Sternberg (1969) recognition } \\
\text { latency: Total correct }\end{array}$ & $\begin{array}{l}\text { Participants are presented with a visually displayed set of digits (set sizes } \\
\text { ranged from } 1 \text { to 5) to memorize. Then a probe item is presented and the } \\
\text { participant indicates whether the probe matches a memory set item. Total } \\
\text { correct score. }\end{array}$ & .413 \\
\hline & $\begin{array}{l}\text { Sternberg (1969) recognition } \\
\text { latency: Intercept }\end{array}$ & $\begin{array}{l}\text { This is the intercept for the regression line of the number correct on the } \\
\text { memory set. }\end{array}$ & -.508 \\
\hline & $\begin{array}{l}\text { Digit span forward } \\
\text { (Wechsler, 1981) }\end{array}$ & $\begin{array}{l}\text { Digits are presented orally, and the participant repeats them in a forward } \\
\text { order. }\end{array}$ & .220 \\
\hline & $\begin{array}{l}\text { Digit span backward } \\
\text { (Wechsler, 1981) }\end{array}$ & $\begin{array}{l}\text { Digits are presented orally, and the participant repeats them in a backward } \\
\text { order. }\end{array}$ & .535 \\
\hline & Spatial cube test (Sequence A) & $\begin{array}{l}\text { Participants reproduce a series of taps tapped by the examiner on a spatial } \\
\text { block array for each of two sequences. }\end{array}$ & .529 \\
\hline & Spatial cube test (Sequence B) & $\begin{array}{l}\text { Participants reproduce a series of taps tapped by the examiner on a spatial } \\
\text { block array for each of two sequences. }\end{array}$ & .628 \\
\hline & $\begin{array}{l}\text { Selective reminding task } \\
\text { (Buschke \& Fuld, 1974) }\end{array}$ & $\begin{array}{l}\text { Participants are presented with a list of words that are to be freely recalled } \\
\text { for } 10 \text { trials. Preceding every new trial after the first, reminders are given } \\
\text { for nonrecalled words. This task yields two long-term and one short-term } \\
\text { measure of performance; only the short-term measure is included in the } \\
\text { short-term memory factor. }\end{array}$ & -.432 \\
\hline \multirow[t]{6}{*}{ Semantic } & Word fluency: Raw & $\begin{array}{l}\text { Timed word fluency. Participant provides category exemplars and words } \\
\text { beginning with letter F, A, S. Raw score. }\end{array}$ & .524 \\
\hline & Word fluency: Total & $\begin{array}{l}\text { Timed word fluency. Participant provides category exemplars and words } \\
\text { beginning with letter F, A, S. Total score. }\end{array}$ & .430 \\
\hline & $\begin{array}{l}\text { Kaplan oral task (Kaplan, } \\
\text { Goodglass, \& Weintraub, 1978) }\end{array}$ & The participant names pictured objects. & .788 \\
\hline & $\begin{array}{l}\text { WAIS Vocabulary } \\
\text { (Wechsler, 1981) }\end{array}$ & $\begin{array}{l}\text { The participant provides definitions of words, and a scaled score is } \\
\text { calculated. }\end{array}$ & .798 \\
\hline & $\begin{array}{l}\text { Remote memory of } 1960 \text { s } \\
\text { (Albert, Butters, \& Levin, } \\
\text { 1979) }\end{array}$ & $\begin{array}{l}\text { In this task, the participant is tested for recognition of famous faces of the } \\
\text { 1960s, with cues (first phonological cues, then semantic cues) provided to } \\
\text { assist recall. }\end{array}$ & .662 \\
\hline & $\begin{array}{l}\text { Remote memory of 1970s } \\
\text { (Albert, Butters, \& Levin, } \\
\text { 1979) }\end{array}$ & $\begin{array}{l}\text { In this task, the participant is tested for recognition of famous faces of the } \\
1970 \text { s, with cues (first phonological cues, then semantic cues) provided to } \\
\text { assist recall. }\end{array}$ & .769 \\
\hline \multirow[t]{6}{*}{ Verbal episodic } & Word recognition (errors) & $\begin{array}{l}\text { This task involves recognition of words presented in the prior selective re- } \\
\text { minding task. Number of errors. }\end{array}$ & -.472 \\
\hline & Word recognition (total score) & $\begin{array}{l}\text { This task involves recognition of words presented in the prior selective re- } \\
\text { minding task. Total score. }\end{array}$ & .529 \\
\hline & $\begin{array}{l}\text { Selective reminding long-term } \\
\text { storage score } \\
\text { (Buschke \& Fuld, 1974) }\end{array}$ & $\begin{array}{l}\text { The participant is presented with a series of words and attempts free recall } \\
\text { for } 10 \text { trials; preceding every new trial after the first, reminders are given for } \\
\text { nonrecalled words. Long-term storage score. }\end{array}$ & .472 \\
\hline & $\begin{array}{l}\text { Selective reminding } \\
\text { consistent long-term storage } \\
\text { score (Buschke \& Fuld, 1974) }\end{array}$ & $\begin{array}{l}\text { The participant is presented with a series of words and attempts free recall } \\
\text { for } 10 \text { trials; preceding every new trial after the first, reminders are given for } \\
\text { nonrecalled words. Consistent long-term storage score. }\end{array}$ & .565 \\
\hline & Prose memory & This task involves delayed recall of story propositions. & .485 \\
\hline & Paired associates & $\begin{array}{l}\text { This task involves memory (cued verbal recall) for paired associates when } \\
\text { shown cue words or pictures. }\end{array}$ & .498 \\
\hline \multirow[t]{2}{*}{ Visual episodic } & $\begin{array}{l}\text { Face acquisition and } \\
\text { recognition (Milner, 1968) }\end{array}$ & $\begin{array}{l}\text { The participant studies faces on a card and is asked to select familiar faces } \\
\text { from a second card. Number correct score. }\end{array}$ & .582 \\
\hline & $\begin{array}{l}\text { Design recognition } \\
\text { (Kimura Recurring } \\
\text { Figures Test; Kimura, 1963) }\end{array}$ & $\begin{array}{l}\text { The participant is presented a set of designs and chooses from a larger set } \\
\text { those which were seen before. Total correct score. }\end{array}$ & .457 \\
\hline
\end{tabular}

Note-Factor loadings are from Herrmann et al., 2001; all loadings are significant at $p<.05$.

ported in Herrmann et al. (2001). Then, to investigate the relationship between brain lesion class and memory performance, we performed four ANCOVAs, one for each of the four memory factors. In each analysis, we included data from individuals in lesion classes with at least 9 members, and the normal control group. In each of the four analyses, factor scores served as the dependent variable and lesion class (including the normal control group) 
Table 2

Adjusted Mean Factor Scores for Memory Factors As a Function of Lesion Class (Covariates = Total Volume Loss, Total Score on the Beck Depression Inventory, and Whether the Participant Had Been Diagnosed With Substance Dependence)

\begin{tabular}{|c|c|c|c|c|c|c|}
\hline \multirow[b]{2}{*}{ Lesion Class } & \multirow[b]{2}{*}{$n$} & \multirow[b]{2}{*}{ Lesion Characteristics } & \multicolumn{4}{|c|}{ Memory } \\
\hline & & & $\begin{array}{l}\text { Short } \\
\text { Term }\end{array}$ & Semantic & $\begin{array}{l}\text { Verbal } \\
\text { Episodic }\end{array}$ & $\begin{array}{l}\text { Visual } \\
\text { Episodic }\end{array}$ \\
\hline 2 & 17 & Right anterior temporal, uncus, some frontal & $3.93^{* * *}$ & 12.88 & 13.06 & 4.26 \\
\hline 5 & 13 & Bilateral cerebellar to occipital, some parietal & $3.18^{* * *}$ & 12.04 & 11.37 & 4.06 \\
\hline 6 & 9 & Large right frontal-temporal-parietal & $3.24^{* * *}$ & 12.41 & 10.91 & 3.98 \\
\hline 7 & 10 & Large left parietal-occipital, some with temporal; right parietal, metal & & & & \\
\hline & & fragments & $1.72^{* * *}$ & 10.31 & $6.08^{* * *}$ & 4.12 \\
\hline 8 & 16 & Right parietal-occipital & $3.06^{* * *}$ & 11.81 & 12.16 & 3.97 \\
\hline 10 & 21 & $\begin{array}{l}\text { Large right dorsofrontal; some with bifrontal, some parietal; metal } \\
\text { fragments }\end{array}$ & $3.55^{* * *}$ & 11.56 & $11.20^{* *}$ & 4.35 \\
\hline 11 & 14 & Large left parietal-occipital, metal & $3.09^{* * *}$ & 11.53 & $10.54^{* *}$ & 4.18 \\
\hline 13 & 18 & $\begin{array}{l}\text { Bilateral frontal poles, more frequently on right than left; mesial } \\
\text { frontal; metal }\end{array}$ & $3.46^{* * *}$ & 11.83 & $10.74^{* *}$ & 4.37 \\
\hline 15 & 13 & Left frontal, some with extension & $2.50^{* * *}$ & $9.79^{* * *}$ & $9.93^{* * *}$ & 4.29 \\
\hline 20 & 9 & Bifrontal, greater loss on right, metal & $3.65^{* * *}$ & 12.62 & 11.04 & 3.96 \\
\hline 21 & 16 & Left temporal, with some frontal & $3.11^{* * *}$ & $10.20^{* * *}$ & $8.39^{* * *}$ & 4.52 \\
\hline 22 & 20 & Left dorsofrontal-parietal & $2.96^{* * *}$ & 11.41 & $10.62^{* * *}$ & 4.71 \\
\hline 201 & 12 & Right anterior temporal, right mesial frontal cortex & $3.94^{* * *}$ & 12.43 & 12.05 & 4.82 \\
\hline 202 & 127 & $\begin{array}{l}\text { Left temporal-occipital, third ventricle, right anterior convexity } \\
\text { cortex, left cortex and white matter medial anterior }\end{array}$ & $3.79^{* * *}$ & 12.45 & $12.15^{* * *}$ & 4.52 \\
\hline 204 & 34 & Left temporal-occipital, right superior colliculus anterior mesial & $3.55^{* * *}$ & 12.53 & $11.68^{* *}$ & 4.54 \\
\hline 206 & 9 & $\begin{array}{l}\text { Left posterior convexity cortex posterior, right basal ganglia internal } \\
\text { capsule, left basal ganglia \& insular cortex, left mesial cortex anterior }\end{array}$ & $3.31^{* * *}$ & 12.46 & 11.82 & 4.11 \\
\hline 301 & 17 & Left and right cortex, white matter medial and lateral & $3.36^{* * *}$ & 11.40 & $10.36^{* * *}$ & 4.44 \\
\hline 302 & 11 & $\begin{array}{l}\text { Right anterior temporal; right temporal-occipital; right basal ganglia; } \\
\text { left frontal gyrus rectus }\end{array}$ & $3.23^{* * *}$ & 12.22 & 11.08 & 4.25 \\
\hline 304 & 14 & $\begin{array}{l}\text { Right mesial cortex anterior, right cortex and white matter medial } \\
\text { anterior, right corona radiate anterior, right convexity cortex anterior }\end{array}$ & $3.10^{* * *}$ & 11.93 & $10.65^{* *}$ & 4.60 \\
\hline 305 & 9 & $\begin{array}{l}\text { Left basal ganglia insular cortex, left genu of corpus callosum, left } \\
\text { basal ganglia, thalamus, left temporal-occipital }\end{array}$ & $3.09^{* * *}$ & 10.44 & 10.84 & 4.31 \\
\hline 307 & 15 & Right frontal to ventricle; some temporal, metal fragments & $3.63^{* * *}$ & 11.63 & $11.03^{*}$ & 4.36 \\
\hline 310 & 9 & Left frontal to ventricle, some temporal, metal fragments & $3.71^{* * *}$ & 12.44 & $10.17^{*}$ & 4.14 \\
\hline Normal controls & 84 & & 6.39 & 12.65 & 14.13 & 4.49 \\
\hline
\end{tabular}

Note-Classes identified by numbers less than 100 were the result of the first mixture model analysis. Classes whose numbers are in the 300 s are from the second mixture model analysis, based on the largest class $(n=303)$ from the first analysis. Classes whose numbers are in the 200s are from the final mixture model analysis, based on the largest class $(n=211)$ from the second analysis. ${ }^{*} p<.05 .{ }^{* *} p<.01 .{ }^{* * *} p<.001$.

as the between-subjects variable. Covariates included the following: total volume of brain loss (in cc), total score on the Beck Depression Inventory (BDI; Beck, Ward, Mendelson, Mock, \& Erbaugh, 1961), and whether the individual had been treated for drug or alcohol dependence. For each effect of lesion location significant at $p<.05$, we report standard statistics, as well as the effect size, as measured by partial eta-squared $\left(\eta_{\mathrm{p}}^{2}\right) .{ }^{1}$ Table 2 provides the adjusted memory factor score means for each class, as well as for normal controls.

STM. The effect of lesion class was highly significant $\left[F(22,480)=24.87, p<.001, \eta_{\mathrm{p}}^{2}=.533\right]$. Follow-up Tukey tests revealed that the STM performance of all 22 brain lesion classes was significantly worse than that of the control group (see Table 2).

Semantic memory. In this analysis, the effect of lesion class was again significant $[F(22,480)=2.24, p<$ $\left..01, \eta_{\mathrm{p}}^{2}=.093\right]$. Follow-up Tukey tests revealed that only Classes 15 and 21 showed deficits in semantic memory in comparison with normal controls (see Table 2).

Verbal episodic memory. In this analysis, the effect of lesion class was significant $[F(22,480)=4.19, p<.001$, $\left.\eta_{\mathrm{p}}^{2}=.161\right]$. Follow-up Tukey tests revealed that Classes 7 , $10,11,13,15,21,22,202,204,301,304,307$, and 310 demonstrated deficits in visual episodic memory in comparison with normal controls (see Table 2).

Visual episodic memory. This analysis yielded no significant effect of lesion class.

\section{Comparisons of All Brain-Injured Individuals and Normal Controls}

Because the analyses above were restricted to classes with sample sizes of 9 or more, the data of some braininjured participants, including those with the greatest volume loss, were not included. Therefore, we conducted another series of ANCOVAs, this time comparing two groups: all brain-injured individuals and normal controls. Each test compared performance on one of the four memory factors, as measured by factor scores, and included the same covariates used in the previous analyses.

STM. Brain-injured participants' STM performance was worse than normal controls' $[F(1,582)=451.64, p<$ $\left..001, \eta_{\mathrm{p}}^{2}=.437\right]$.

Semantic memory. In contrast with the analyses of semantic memory reported above, there was no significant effect of brain injury on semantic memory.

Verbal episodic memory. Individuals in the braininjured group performed worse than normal controls on 
Table 3

Effect Sizes (Compared With Normal Controls) and Adjusted Mean Factor Scores As a Function of Region of Brain Lesion (Covariates = Total Volume Loss, Total Score on the Beck Depression Inventory, and Whether the Participant Had Been Diagnosed With Substance Dependence)

\begin{tabular}{|c|c|c|c|c|c|c|c|c|}
\hline \multirow[b]{3}{*}{ Brain Region } & \multicolumn{8}{|c|}{ Memory Type } \\
\hline & \multicolumn{2}{|c|}{ Short Term } & \multicolumn{2}{|c|}{ Semantic } & \multicolumn{2}{|c|}{ Verbal Episodic } & \multicolumn{2}{|c|}{ Visual Episodic } \\
\hline & $\eta_{\mathrm{p}}^{2}$ & $M$ & $\eta_{\mathrm{p}}^{2}$ & $M$ & $\eta_{\mathrm{p}}^{2}$ & $M$ & $\eta_{\mathrm{p}}^{2}$ & $M$ \\
\hline Frontal & .580 & $3.30^{* * *}$ & .046 & $11.38^{* *}$ & .209 & $10.23^{* * *}$ & & 4.28 , n.s. \\
\hline Dorsofrontal & 390 & $3.29^{* * *}$ & & 11.49 , n.s. & .114 & $10.94^{* *}$ & .036 & $4.51^{*}$ \\
\hline Parieto-occipital & .480 & $3.08^{* * *}$ & & 11.56 , n.s. & .071 & $10.75^{* *}$ & & 4.16, n.s. \\
\hline Temporal & .503 & $3.34^{* * *}$ & & 11.64, n.s. & .128 & $10.26^{* * *}$ & & 4.28 , n.s. \\
\hline Right hemisphere & .489 & $3.37^{* * *}$ & & 11.92 , n.s. & .070 & $11.15^{* * *}$ & & 4.20 , n.s. \\
\hline Left hemisphere & .517 & $2.93^{* * *}$ & & 11.06 , n.s. & .123 & $9.77^{* * *}$ & & 4.33 , n.s. \\
\hline Normal controls & & 6.39 & & 12.65 & & 14.13 & & 4.49 \\
\hline
\end{tabular}

Note-Typeface of effect sizes reflects effect size categories: Effect sizes in plain bold typeface are more than twice the magnitude of Cohen's (1988) criterion for large effect size; effect sizes in bold italics meet only his criterion for large effect size; plain typeface indicates medium effect sizes; italic plain typeface indicates small effect sizes. $p$ values for factor scores refer to difference from normal controls. ${ }^{*} p<$ $.05{ }^{* *} p<.01 .{ }^{* * *} p<.001$.

verbal episodic memory $[F(1,582)=33.75, p<.001$, $\left.\eta_{\mathrm{p}}^{2}=.055\right]$. Although this effect size is significant, it is much smaller than that observed for STM.

Visual episodic memory. Brain-injured individuals' visual episodic memory performance was not significantly different from that of normal controls.

\section{Comparisons of Traditional Lesion Location Groups and Normal Controls}

In this set of analyses, we characterized each braininjured veteran as to whether his lesion could be classified as frontal, dorsofrontal, parieto-occipital, temporal, right hemisphere, or left hemisphere, on the basis of the mixture model class to which he had been assigned. These classifications were not mutually exclusive both because an individual could experience damage across lobes depending on the trajectory of the shrapnel in the brain and because the right/left distinction could also apply to any of the other locations. Therefore, we conducted a final series of ANCOVAs; in each, participants with lesions in a particular location were compared with the normal control group, for each type of memory (e.g., one analysis compared the STM performance of participants with frontal lobe lesions and that of normal controls). In each analysis, we used the same covariates as previously: total volume loss, BDI score, and whether the veteran had been treated for substance dependence.

The results of these analyses are presented in Table 3. Again, the STM results differ from those of the other three types of memory we investigated. STM deficits occurred for all lesion locations; the only other type of memory for which this pattern was true was verbal episodic memory, where the effect sizes were much smaller. In addition, for all lesion locations, as in the previous analyses, the effect sizes for STM were far greater than the effect size for any other type of memory assessed. In fact, if one considers our measure of effect size, $\eta_{\mathrm{p}}^{2}$, to be comparable to the squared correlation between a treatment and a dependent variable, the effect sizes for STM are more than twice the size traditionally considered "large" $\left(r^{2}=.138\right.$; Cohen, 1988).

\section{DISCUSSION}

Our findings consistently demonstrate that regardless of lesion location, and regardless of how the lesion site is characterized, Vietnam veterans with brain lesions resulting from penetrating head injuries consistently showed subnormal STM 12-15 years postinjury. Furthermore, the effect sizes for STM are strikingly higher than those for the other three types of memory investigated. These effects persist despite frequent concomitant effects of depressive symptomatology and substance dependence. They contrast sharply with those regarding the effects of lesion location on semantic memory and on visual episodic memory, where performance is dependent on lesion location. The results for verbal episodic memory were, like those for STM, significant for all lesion locations in the analyses based on traditional lesion location. However, in these analyses, as in all of the others, the effect sizes for STM are much greater than those for the other three types of memory investigated.

These findings suggest that, although some areas of the brain may play particularly important roles in carrying out STM functions, a penetrating injury anywhere in the brain is likely to disrupt these memory functions notably for decades - a tendency that seems distinctly less pronounced for the other three memory types that we have studied. In contrast, Fuster's (1997) extensive literature review on WM describes associations between WM tasks and dorsolateral lesions in both the frontal and prefrontal areas. Nevertheless, he cautions that there is an interdependence of cognitive functions, as well as many confounding variables and integrated cognitive functions, particularly on memory tasks. For example, several researchers have suggested that the areas for WM act together as part of a neuronal network (Scheibel et al., 2007).

Although our central finding concerns STM difficulties across all lesion classes, our findings regarding injury location and performance on other memory factors are generally consistent with those in the neuropsychological literature. Semantic memory deficits were observed 
for individuals in Classes 15 and 21, who experienced damage in the left frontal lobe. Deficits in verbal episodic memory were more commonplace, occurring in classes marked by left frontal, left posterior temporal, and left parietal lesions - findings loosely consistent with findings reporting that such deficits are associated with left temporal and frontal lobe functioning (Chelune \& Bornstein, 1988; Wagner, 2002). Our results regarding the visual episodic memory factor were more surprising: We found very little evidence that lesion location was related to performance on visual episodic memory tasks. However, deficits on these tasks are frequently associated with right temporal lobe functioning (Kimura, 1963; Milner, 1968), and our sample included very few individuals with this type of lesion. Another possible explanation is that because visual stimuli can be processed either visually or via verbal mediation strategies, performance on visual memory tasks may be tied less specifically to particular lesion locations. In addition, we suspect that these discrepancies result from the nature of the injuries studied here, which typically included lesions across a variety of brain structures.

Clearly, however, the most striking finding reported here is the fact that STM performance is strikingly vulnerable to brain injury. No matter where lesions were observed, the STM performance of brain-injured veterans was uniformly worse than that of normal control veterans. Furthermore, effect sizes associated with these deficits were very large. These results imply that the performance of STM tasks depends on normal functioning of a wide variety of brain locations. In fact, it appears to require a relatively intact, complete brain. Clinically, our findings strongly suggest that both in evaluating the psychological sequelae of penetrating head injuries and in developing rehabilitative strategies for penetrating head injury patients, particular attention should be paid to the likely possibility of notable STM loss.

In terms of an understanding of brain function, a plausible implication of our findings is that the performance of STM tasks is distributed across many, possibly all, brain locations. They suggest that STM is, in some sense, broadly represented across the brain. Such an outcome could be the result of several phenomena. For example, STM tasks may have particularly high attentional requirements, so that brain injury of any kind reduces attention or affects arousal in ways that reduce performance on STM tasks. Our findings also raise the possibility that STM may be independent of stored content, because it is apparently disrupted by lesions in virtually any location. More generally, our results suggest that present conceptualizations of STM may require revision.

\section{AUTHOR NOTE}

This research was supported in part by the Intramural Program of the $\mathrm{NIH}$, National Institute of Mental Health, and the National Institute of Neurological Disorders and Stroke, of the U.S. Department of Health and Human Services. The Vietnam Head Injury Study (VHIS) was supported under Veterans Administration Contract IGA V101 (91) M-79031-2 with the cooperation and support of the U.S. Army, Navy, and Air Force, and the American Red Cross. C.S., L.J.C., and A.J.R. are affiliated with the Section on Socio-Environmental Studies of the NIMH (NIH); A.M.S. and J.G., with the Cognitive Neuroscience Section of the National Institute of Neurological Disorders and Stroke (NIH). The views expressed in this article are those of the authors and do not necessarily reflect the official policy or position of the Department of the Navy, Department of Defense, or the U.S. Government. For further information on VHIS, contact J. Grafman, PhD, Chief, Cognitive Neuroscience Section, National Institute of Neurological Disorders and Stroke, Building 10, Room 7D43, MSC 1440, Bethesda, MD 20892-1440 (e-mail: grafmanj@ninds.nih gov). Correspondence should be addressed to C. Schooler, Intramural Research Program, National Institute of Mental Health, 6101 Executive Blvd., Suite 360, Room 362, MSC 8408, Bethesda, MD 20892-8408 (e-mail: carmi.schooler@nih.gov).

\section{REFERENCES}

Akaike, H. (1987). Factor analysis and AIC. Psychometrika, 52, 317-332.

Albert, M. S., Butters, N., \& Levin, J. (1979). Temporal gradients in the retrograde amnesia of patients with alcoholic Korsakoff's disease. Archives of Neurology, 36, 211-216.

Anderson, T. W., \& Rubin, H. (1956). Statistical inference in factor analysis. In J. Neyman (Ed.), Proceedings of the Third Berkeley Symposium on Mathematical Statistics and Probability (Vol. 5, pp. 111-150). Berkeley: University of California Press.

Beck, A. T., Ward, C. H., Mendelson, M., Mock, J., \& Erbaugh, J. (1961). An inventory for measuring depression. Archives of General Psychiatry, 4, 561-571.

Benton, A. L., \& Hamsher, K. (1976). Multilingual aphasia examination. Iowa City: University of Iowa.

BuschKe, H., \& Fuld, P. A. (1974). Evaluating storage, retention, and retrieval in disordered memory and learning. Neurology, 24, 1019-1025.

Chelune, G. J., \& Bornstein, R. A. (1988). WMS-R patterns among patients with unilateral lesions. Clinical Neuropsychologist, 2, 121-132.

CoHen, J. (1988). Statistical analysis for the behavioral sciences (2nd ed.). Hillsdale, NJ: Erlbaum.

Fuster, J. M. (1997). The prefrontal cortex: Anatomy, physiology, and neuropsychology of the frontal lobe (3rd ed.). Philadelphia: LippincottRaven.

Gerton, B. K., Brown, T. T., Meyer-Lindenberg, A., Kohn, P., Holt, J. L., Olsen, R. K., \& Berman, K. F. (2004). Shared and distinct neurophysiological components of the digits forward and backward tasks as revealed by functional neuroimaging. Neuropsychologia, 42, 1781-1787.

Grafman, J., Jonas, B. S., Martin, A., Salazar, A. M., WeingartNER, H., LuDLOW, C., ET AL. (1988). Intellectual function following penetrating head injury in Vietnam veterans. Brain, 111, 169-184

Herrmann, D. J., Schooler, C., Caplan, L. J., Lipman, P. D., GrafMAN, J., Schoenbach, C., ET AL. (2001). The latent structure of memory: A confirmatory factor-analytic study of memory distinctions. Multivariate Behavioral Research, 36, 29-51.

Kane, M. J., Hambrick, D. Z., Tuholski, S. W., Wilhelm, O., Payne, T. W., \& Engle, R. W. (2004). The generality of working memory capacity: A latent-variable approach to verbal and visuospatial memory span and reasoning. Journal of Experimental Psychology: General, 133, 189-217.

Kaplan, E., Goodglass, H., \& Weintraub, S. (1978). The Boston naming test. Boston: Author.

Kimura, D. (1963). Right temporal-lobe damage: Perception of unfamiliar stimuli after damage. Archives of Neurology, 8, 264-271.

Lee, G. P., Loring, D. W., Smith, J. R., \& Flanigin, H. F. (1990). Material specific learning during electrical stimulation of the human hippocampus. Cortex, 26, 433-442.

LeE, G. P., Loring, D. W., \& Thompson, J. L. (1989). Construct validity of material-specific memory measures following unilateral temporal lobe ablations. Psychological Assessment, 1, 192-197.

LEZAK, M. D. (1983). Neuropsychological assessment (2nd ed.). New York: Oxford University Press.

LeZaK, M. D. (1995). Neuropsychological assessment (3rd ed.). New York: Oxford University Press.

Milner, B. (1968). Visual recognition and recall after right temporal lobe excision in man. Neuropsychologia, 6, 191-209.

MiLner, B. (1971). Interhemispheric differences in the localization 
of psychological processes in man. British Medical Bulletin, 27, 272-277.

MuthÉN, B. [O.], \& MuthÉN, L. K. (2000). Integrating person-centered and variable-centered analyses: Growth mixture modeling with latent trajectory classes. Alcoholism: Clinical \& Experimental Research, 24, 882-891.

Muthén, B. [O.], \& Shedden, K. (1999). Finite mixture modeling with mixture outcomes using the EM algorithm. Biometrics, 55, 463-469.

Muthén, L. K., \& MuthéN, B. O. (1998-2004). Mplus user's guide: Statistical analysis with latent variables (3rd ed.). Los Angeles: Author.

Salazar, A. M., Grafman, J. H., Vance, S. C., Weingartner, H., Dillon, J. D., \& Ludlow, C. (1986). Consciousness and amnesia after penetrating head injury: Neurology and anatomy. Neurology, 36, 178-187.

Sass, K. J., Spencer, D. D., Spencer, S. S., Novelly, R. A., WilLiamson, P. D., \& Mattson, R. H. (1988). Corpus callosotomy for epilepsy. II. Neurologic and neuropsychological outcome. Neurology, 38, 24-28.

Scheibel, R. S., Newsome, M. R., Steinberg, J. L., Pearson, D. A., RAUCH, R. A., MAO, H., ET AL. (2007). Altered brain activation during cognitive control in patients with moderate to severe traumatic brain injury. Neurorehabilitation \& Neural Repair, 21, 36-45.
Sclove, S. L. (1987). Application of model-selection criteria to some problems in multivariate analysis. Psychometrika, 52, 333-343.

Smith, M. L., \& Bigel, M. G. (2000). The temporal lobes and memory. In F. Boller \& J. Grafman (Eds.), Handbook of neuropsychology (2nd ed., pp. 49-65). New York: Elsevier.

StERnBERG, S. (1969). Memory-scanning: Mental processes revealed by reaction-time experiments. American Scientist, 57, 421-457.

WAGNer, A. D. (2002). Cognitive control and episodic memory: Contributions from prefrontal cortex. In L. R. Squire \& D. L. Schacter (Eds.), Neuropsychology of memory (3rd ed., pp. 174-192). New York: Guilford.

WeChSLER, D. (1981). WAIS-R manual: Wechsler Adult Intelligence Scale-Revised. New York: The Psychological Corporation.

\section{NOTE}

1. For this and all subsequent analyses including these covariates, results of significance tests for covariates are available from the corresponding author.

(Manuscript received June 13, 2007; revision accepted for publication December 4, 2007.) 